\title{
Efficacy of Auditory Training on Speech Recognition in Children Wearing Hearing Aids
}

\author{
Yewon Lee', Hyekyeong Hwang ${ }^{2}$, Jae Hee Lee ${ }^{1,3}$ \\ ${ }^{1}$ Department of Audiology and Speech-Language Pathology, Hallym University of Graduate Studies, Seoul, Korea \\ ${ }^{2}$ Hearingmedics, Seoul, Korea \\ ${ }^{3}$ HUGS Center for Hearing and Speech Research, Seoul, Korea
}

\author{
청능훈련이 보청기 착용 아동의 어음인지에 미치는 효과 \\ 이예원 ${ }^{1}$ 황혜경 ${ }^{2} \cdot$ 이재희 ${ }^{1,3}$ \\ 한림국제대학원대학교 청각언어치료학과 ${ }^{1}$, 히어링메딕스 ${ }^{2}$, 한림청각언어연구소 ${ }^{3}$
}

\begin{abstract}
Purpose: Auditory training is known to be helpful for reduced speech-in-noise recognition abilities. The purpose of this study was to evaluate the efficacy of 8-week auditory training for children using hearing aids. Also, the retention effect of training was determined from 1-month and 4-month follow-up tests after the completion of training. Methods: Eight children with hearing aids participated in eight sentence-in-noise training sessions over eight weeks (one session per week, 40-minute training per session). Each child completed training lessons concentrating on closed-set speech-in-noise training with matching pictures. To evaluate the efficacy of the auditory training, word recognition score (WRS) and sentence recognition score (SRS) were measured at quiet, 10, 5, $0 \mathrm{~dB}$ signal-to-noise ratio (SNR) conditions. Speech-in-noise performances were assessed immediately after the auditory training and again after one month and four months during which no training conducted. Sentences and talkers for tests were different from those used in the auditory training. The auditory behavior in everyday life questionnaire (ABEL) test was also conducted as a parental subjective questionnaire before and after the auditory training. Results: The word and sentence recognition abilities were significantly improved after the auditory. The improvement was observed in both quiet and noisy conditions, even at the most unfavorable SNR condition. The ABEL score was also enhanced after the auditory training. From the individual data, the 8-week auditory training influenced positively the abilities of speech recognition and parentreported auditory behaviors. Both scores of WRS and SRS in noise were maintained until 4 months after the completion of the auditory training. Conclusion: A 8-week pediatric auditory training may lead to improved speech-in-noise recognition and auditory behaviors in children with hearing aids, regardless of listening conditions. The efficacy of the auditory training was maintained until 4-month follow-up.
\end{abstract}

Key Words: Pediatric auditory training, Aural rehabilitation, Hearing loss, Speech-in-noise recognition.

Received: August 21, 2019 / Revised: September 10, 2019 / Accepted: September 10, 2019

Correspondence: Jae Hee Lee, Department of Audiology and Speech-Language Pathology, Hallym University of Graduate Studies, HUGS Center for Hearing and Speech Research, 427 Yeoksam-ro, Gangnam-gu, Seoul 06197, Korea

Tel: +82-2-2051-4952 / Fax: +82-2-3451-6618 / E-mail: leejaehee@hallym.ac.kr

\section{INTRODUCTION}

2017년 세계보건기구는 전 세계 인구의 5\%가 넘는 3억 6,000 만 명의 사람들이 청력 손실을 가지고 있으며 이 중에 3,200만 명이 아동이라 보고하였다. 아동은 유치원, 학교, 놀이터 등과 같이 다양한 소음이 발생하는 환경에서 생활하게 된다. Park

(cc) This is an Open Access article distributed under the terms of the Creative Commons Attribution Non-Commercial License (https://creativecommons.org/licenses/by-nc/4.0) which permits unrestricted non-commercial use, distribution, and reproduction in any medium, provided the original work is properly cited. et al.(2001)은 국내 도심지에 위치한 초등학교의 경우 수업시간 중 교실 내 소음이 64 69 dBA, 쉬는 시간의 경우 교실 내 소 음이 67 72 dBA이라고 밝혔다. 국외 연구에서도 교실 내 소음 이 48 69 dBA가량이고 주로 관찰된 신호대잡음비가 1 5 dB signal-to-noise ratio (SNR)라 하였다(Crandell \& Smaldino, 2000). Jamieson et al.(2004)은 아동의 나이가 어릴수록 소음 환경에서 의사소통에 더 어려움을 보인다고 하였다. 다양한 소 음이 존재하는 상황에서 청각장애 아동이 학습해야 한다면 언 어 발달, 읽기, 쓰기뿐 아니라 학업, 정서, 인지 발달 면에 있어 
서 부정적인 영향을 받을 수 있다(Crandell \& Smaldino, 2000; Klatte et al., 2010, 2013; Valente et al., 2012). 따라서 보청기 만으로 소음 속 상황에서 의사소통하는 것이 어려운 경우 청 능훈련을 시작하는 것을 고려해야 한다.

청능훈련이란 청각 자극에 반응하는 뇌의 가소성에 기초하 는 것으로, 반복적으로 듣는 연습을 통해 의사소통 능력 개선 을 목표로 한다(Henshaw \& Ferguson, 2013). 청능훈련은 개 개인의 인지 정도와 복합적인 상호 과정을 포함하고 있으며 훈 련을 실시한 영역만 향상되는 것이 아닌 훈련을 시행하지 않은 영역 혹은 인지기능과 감각기관의 상호작용에서 일어나는 통 합 능력이 향상될 수 있다(Moore \& Amitay, 2007). 국외 연구 자들은 다양한 청능훈련 도구와 평가 절차를 통하여 긍정적인 청능훈련 효과를 보고하였다(Alonso \& Schochat, 2009; Lotfi et al., 2016; Mishra et al., 2015, 2018; Rochette \& Bigand, 2009; Rochette et al., 2014; Sullivan et al., 2013; Wu et al., 2007). 예를 들어 Wu et al.(2007)은 10명에게 컴퓨터를 활 용한 청능훈련을 10 주간 시행하였고 훈련 후, 어음인지도가 증 가하였고 그 효과는 훈련 종료 후 2개월까지 유지되었다고 하 였다. Roman et al.(2016)의 연구에서 인공와우 사용 아동에게 청능훈련을 시행한 결과 훈련에 참여한 아동의 인지도가 향상 하였고 특히 어릴수록 훈련의 효과는 더 컸다. 13 명의 인공와 우 사용 아동에게 소음하 어음인지 청능훈련을 시행한 Mishra et al.(2015)은 훈련 후 소음하 어음인지도가 증가하였을 뿐 아 니라 훈련에 사용하지 않은 숫자인지 능력도 증가하였으며, 훈 련 종료 3주 후까지 효과가 유지되었음을 보고하였다. Mishra et al.(2018)은 14명의 인공와우 사용 아동에게 5 주간 순방향숫 자기억하기 훈련을, 13 명의 다른 인공와우 사용 아동에게는 역 방향숫자기억하기 훈련을 시행하였다. 훈련 후 작업기억 능력 이 향상하고 훈련 후 5 주 후에도 효과가 유지되었으나 소음하 어음인지의 향상으로까지 일반화되지 않았음을 확인하였다. Nanjundaswamy et al.(2018)은 컴퓨터 기반 청능훈련 도구를 분석하였고, 각각의 청능훈련 도구가 소음하 어음, 다화자 어 음, 시청각 어음, 음악, 환경음 등의 다양한 자극음을 콘텐츠로 포함하고 있으나 훈련 효과를 검증하는 데 사용할 평가 도구가 제한적임을 밝혔다.

국내의 경우 난청 성인 및 노인을 대상으로 실시 가능한 청 능훈련 도구가 다수 발표되었으나(Ahn \& Lee, 2016; Baek \& Lee, 2016; Lee et al., 2016b; Lim \& Bahng, 2016) 아동을 대 상으로 한 청능훈련 도구 개발 및 효과 검증에 대한 연구는 제 한적이다(Park \& Han, 2019). Rayes et al.(2019)은 인공와우 착용 아동을 대상으로 청능훈련의 효과를 밝힌 다양한 선행연 구를 리뷰한 결과, 많은 연구에서 청능훈련의 효과를 밝혔으나 훈련에 사용하지 않은 자극음에 대한 인지도, 삶의 질이 향상
하였는지 밝힌 연구가 부족하고 훈련 효과가 장기적으로 유지 되는지 보고한 연구가 제한적이라고 밝혔다.

최근 Lee et al.(2017)은 3 5개의 단어로 구성된 문장을 이용 한 아동용 청능훈련 도구를 개발하고 건청 아동을 대상으로 목록 간 난이도를 검증하였다. 본 연구에서는 Lee et al.(2017) 의 아동용 청능훈련 도구를 이용하여 8주간의 청능훈련을 시 행한 후 보청기 착용 난청 아동의 어음인지도가 향상하는지, 부모가 답한 주관적 설문 결과 또한 긍정적으로 변화하는지 확인하고자 하였다. 청능훈련의 효과를 보고할 때 훈련 효과가 일시적인지 아니면 장기적으로 훈련 효과가 유지(retention)되 는지를 확인하는 것이 중요하다. 청능훈련의 효과를 보고한 선 행연구 대부분이 청능훈련 종료 3주 후(Mishra et al., 2015), 1 개월 후(Green et al., 2019; Oba et al., 2011), 2개월 후(Wu et al., 2007), 3개월 후(Sullivan et al., 2013)에 재평가를 시행하 여 훈련 효과가 유지되는지 확인하였다. 위의 선행연구 모두 훈 련 효과가 유지되었다고 보고하였으므로 본 연구에서는 훈련 종료 4개월 후에 재평가를 시행하여 훈련의 효과가 유지되는지 평가하였다.

\section{MATERIALS AND METHODS}

\section{연구 대상}

본 연구에는 보청기 착용 아동 8 명(남아 4명, 여아 4명)이 대 상자로 참여하였다. 8명 아동의 평균 연령은 만 6세 8개월범위: 만 5세 7세 4개월, standard deviation (SD): 9.6]이었고, 대상 아 동의 보청기 착용 기간이 평균 28개월이었다(SD: 15.2). 8명 대 상 아동 중 7명은 양이에 보청기를 착용하고 있었으며, 1 명은 좌측 귀에 보청기를 우측 귀에는 인공와우를 착용하고 있었다. 보청기를 착용하기 전 $500,1,000,2,000 \mathrm{~Hz}$ 의 평균순음역치 (pure tone threshold average, PTA)를 계산한 결과, 우측 귀의 경우 평균 $57.4 \mathrm{~dB} \mathrm{HL(SD:} \mathrm{15.3),} \mathrm{좌측} \mathrm{귀의} \mathrm{평균} \mathrm{PTA는} 59.2$ $\mathrm{dB}$ HL(SD: 18.3)이었다. 보청기 착용 시 평균 PTA는 우측 귀가 33.8 dB HL(범위: 28.3 43.3 dB HL, SD: 5.6), 좌측 귀가 37.1 $\mathrm{dB}$ HL(범위: 23.3 55.0 dB HL, SD: 9.8)이었다.

취학 전 아동의 수용언어 및 표현언어 발달 척도(preschool receptive-expressive language scale)를 통해 대상 아동의 언 어 발달을 평가한 결과 $(\mathrm{Kim}, 2000)$, 본 연구에 참여한 난청 아 동의 평균 수용언어 연령은 5 세(SD: 0.5$)$, 평균 표현언어 연령은 4.6세(SD: 0.9)였다. 표준화된 한국어음청각검사도구를 이용하여 아동 개개인의 쾌적 레벨에서 단어와 문장인지도를 측정한 결과 (Lee et al., 2010), 평균 단어인지도와 문장인지도는 60.0\%(SD: 14.8), 68.8\%(SD: 26.7)였다.

훈련에 참여하기 전 대상 아동의 보호자는 연구의 목적과 방 
법에 대하여 자세한 설명을 듣고 이해한 후 참여 동의서에 서명 을 하였다. 매번 훈련을 시작하기 전 성능 분석 장비(Audioscan Verifit2, Audioscan, Ontario, Canada)를 이용하여 아동 개개 인이 선호하는 보청기 적합 상태를 확인하였고, 매번 훈련을 시 작하기 전 보청기의 이상 유무를 확인한 후 훈련을 진행하였다.

\section{평가 방법 및 장비}

청능훈련 효과를 평가하기 위해 청능훈련 시작 전(pre-training, 0주)과 8주의 청능훈련이 끝난 후(post-training, 8주)에 조용한 상황(in quiet)과 $10,5,0 \mathrm{~dB} \mathrm{SNR에서} \mathrm{단어인지도} \mathrm{및}$ 문장인지도를 측정하여 비교하였다. 훈련을 종료한 지 1 개월 후 (1-month follow-up), 4개월 후(4-month follow-up)에 동일한 검사를 진행하여 훈련 4개월 후까지 인지도가 유의하게 감소하 지 않고 유지되는지를 확인하고자 하였다. 청능훈련 효과를 평 가하기 위해 조용한 상황(quiet)과 $10,5,0 \mathrm{~dB} \mathrm{SNR}$ 의 다화자 소음하 조건에서 한국어음청각검사도구(Lee et al., 2010)를 이 용하여 어음인지도 검사를 시행하였고, 목표 단음절어 및 문장 은 일상 평균 대화 레벨인 $65 \mathrm{~dB} \mathrm{SPL에서} \mathrm{제시하였다.} \mathrm{소음하}$ 어음청각검사를 위해 목표 단어 혹은 문장과 다화자 배경 소 음(Shin \& Lee, 2010)의 실효 값(root mean square)이 일정하 도록 조절하였고(Adobe Audition CC 2015, Adobe System Inc., San Jose, CA, USA), 청능훈련 효과의 평가를 위해 청력 검사기(GSI AudioStar Pro, Grason-stadler, Eden Prairie, $\mathrm{MN}$, USA), 음장검사용 스피커(JBL Control 1 Pro, JBL professional, Northridge, CA, USA)를 사용하였다.

위의 객관적 평가 외에 한국어 버전 일상생활 청각행동 설문 지(auditory behavior in everyday life questionnaire, ABEL) (Choi et al., 2017a)를 부모에게 조사하여 청능훈련 전후(0주와 8주) $\mathrm{ABEL}$ 점수 변화를 확인하였다. 한국어 버전 $\mathrm{ABEL}$ 은 설 문 문항이 짧고 간결하며 평가 도구로써 신뢰도, 타당도를 검증 하였다. 따라서 청능훈련 전후 $\mathrm{ABEL}$ 설문을 시행하여 청능훈 련 후 부모가 느끼는 아동의 청각 행동의 변화뿐 아니라 청각 경험에 따른 심리사회적 기술 면에 변화가 있는지 알아보고자 하였다.

\section{청능훈련 도구 및 절차}

청능훈련은 8 주간 총 8 회(주당 1 회) 실시하였으며, 매 회기당 훈련 40 분, 부모 상담 10 분으로 구성하여 진행하였다. 본 연구 에서는 Lee et al.(2017)이 발표한 아동용 청능훈련 문장 음원 을 사용하였다. 개발 당시 1,616 개의 음원을 조용한 환경과 6 , $3,0 \mathrm{~dB} \mathrm{SNR}$ 의 소음 환경에서 제시 가능하도록 제작하여 훈련 에 총 6,464 개의 문장 음원을 사용할 수 있다. 각 문장에 부합 하는 그림판이 존재하고, 목표 문장 내에 최소 2 개, 최대 4 개의
중심 단어를 포함하고 있다.

청능훈련은 소음 측정기(TES-1350A sound level meter, TES Electrical Electronic Corp., Taipei, Taiwan)를 사용하여 소음 레벨이 $40 \mathrm{dBA}$ 이하의 방에서 시행하였다. 훈련용 문장 음원 은 컴퓨터(DM500T8A-A58, Samsung, Seoul, Korea)와 음장 스피커(Realtek High Definition Audio, Samsung)를 통해 약 $65 \mathrm{~dB}$ SPL에서 제시하였다. 훈련 시 목표 문장을 듣고 틀리게 답을 하는 경우 최대 5 회까지 반복하여 제시하였다.

청능훈련 시 난이도가 너무 쉬운 경우 대상 아동이 지루해할 수 있고, 너무 어려운 경우 좌절감과 스트레스를 느낄 수 있다. 따라서 훈련 시 대상 아동이 50 80\%의 정반응을 보일 수 있는 난이도를 유지하고자 하였다. 난이도 조절을 위해 훈련에 사용 할 문장 내 중심 단어의 수(최소 2 개 $\rightarrow$ 최대 4 개), 반응 방법(그 림판 보기에서 중심 단어 고르기(closed-set) $\rightarrow$ 문장 듣고 따라 말하기(open-set), 신호대잡음비(소음 강도를 증가), 그림판 보 기의 수(최소 4 개 $\rightarrow$ 최대 16 개의 그림 보기)를 조절하는 방법 을 사용하였다. 예를 들어 목표 문장이 “기린이 배를 탄다."인 경우 중심 단어가 '기린'과 ‘배'이다. Figure 1에 제시한 것처럼 아동의 집중 정도에 따라 8개의 그림판 보기 중 목표 그림('배 를 타고 있는 기린)을 고르거나(예시 1) 16 개의 그림판(8개의 동물, 8 개의 탈 것 그림) 중 '기린'과 '배’의 2가지 그림(예시 2)을 선택하게 하였다.

\section{통계 분석}

자료는 SPSS version 20.0 (IBM Corp., Armonk, NY, USA) 소프트웨어를 사용하여 분석하였다. 그룹 내 독립 변수인 평가 시기(평가 전후), 평가 조건(quiet, $10,5,0 \mathrm{~dB} \mathrm{SNR}$ )에 따라 종 속변수인 단어인지도 혹은 문장인지도가 유의하게 달라지는지 확인하기 위해 각각 반복 측정된 이원배치 분산분석을 실시하 였다. Mauchly 구형성 검정 결과 구형성 가정에 위배되는 경우 Greenhouse-Geisser의 수정된 자유도와 F 값을 확인하였다. 청능훈련 효과의 유지를 확인하기 위해 훈련 후, 훈련 종료 1 개 월 후, 훈련 종료 4 개월 후의 단어인지도 혹은 문장인지도의 변 화를 확인하였다. 훈련 전후 $\mathrm{ABEL}$ 설문 결과를 비교하기 위해 Wilcoxon 부호순위검정(signed rank test) 분석을 시행하였다. 더불어 Spearman 상관 분석을 통해 객관적 인지도와 주관적 설문 평가의 결과에서 훈련 후 향상 정도 간 상관성을 확인하 였다. 모든 통계 분석은 유의 수준 0.05 미만에서 검증하였다.

\section{RESULTS}

\section{청능훈련에 따른 평균 어음인지도 향상}

Figure 2는 평가 시기(훈련 전, 훈련 후, 그리고 훈련 종료 1 


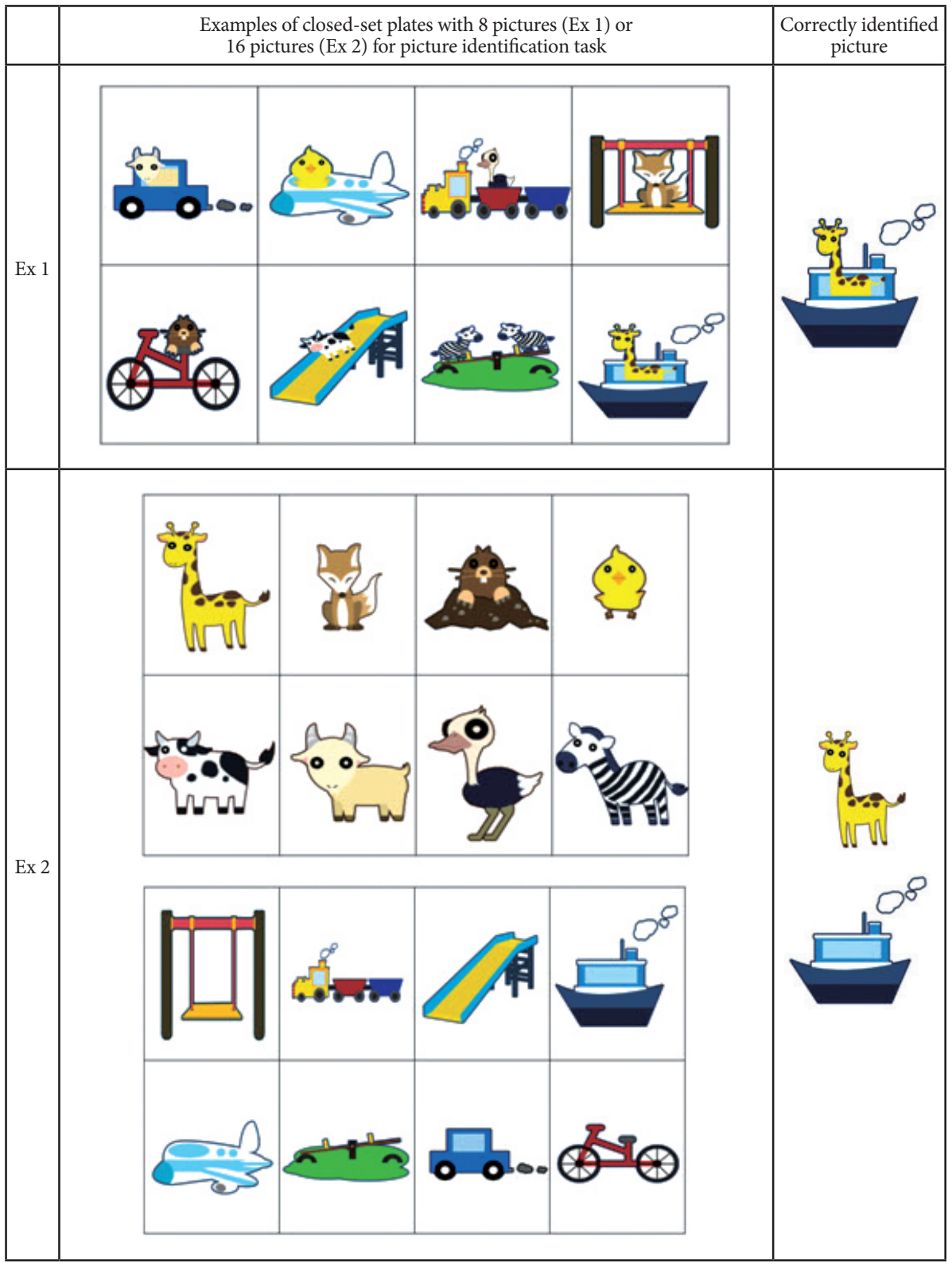

Figure 1. Examples of closed-set plates with 8 or 16 pictures for picture identification task. Ex: example.
개월 후, 4개월 후)에 따라 조용한 상황과 소음하 상황(10, 5, 0 $\mathrm{dB}$ SNR)에서 측정한 단어인지도와 문장인지도를 보여준다. 먼 저 단어인지도를 살펴보면 훈련 전, 훈련 후, 훈련 종료 1 개월 후, 훈련 종료 4 개월 후에 측정한 조용한 상황에서의 평균 단어 인지도는 $60.0 \%, 71.5 \%, 71.3 \%, 73.6 \%(\mathrm{SD}: 14.8,15.9,13.2,12.2)$ 였다. $10 \mathrm{~dB} \mathrm{SNR}$ 의 소음 상황에서 평균 단어인지도를 평가 시 기의 순서대로 나열하면 $45.5 \%, 59.0 \%, 58.0 \%, 60.8 \%$ (SD: 15.0, 13.8, 13.9, 12.5), $5 \mathrm{~dB} \mathrm{SNR}$ 의 소음하에서 구한 평균 단어인지도 는 같은 순서대로 $28.5 \%, 47.0 \%, 45.0 \%, 48.8 \%$ 였다(SD: 14.7 , $15.8,16.0,11.8)$. 본 연구에서 가장 어려운 듣기 조건인 $0 \mathrm{~dB}$ $\mathrm{SNR}$ 에서 측정한 평균 단어인지도는 $14.5 \%, 27.0 \%, 25.5 \%$, 26.4\%였다(SD: 13.7, 20.8, 18.4, 13.7).
통계 분석 결과 훈련 전후에 따라 $[\mathrm{F}(1,7)=53.8, p<0.001]$, 듣기 조건에 따라 $[\mathrm{F}(3,21)=86.4, p<0.001]$ 단어인지도가 유 의하게 달랐다. 훈련 전에 비해 훈련 후 모든 조건에서 11 19\% 가량 증가하여 이원상호작용은 유의하지 않았다 $[\mathrm{F}(3,21)=$ $1.48, p>0.05]$. Bonferroni 대응별 다중비교 결과를 확인한 결과 네 가지 듣기 조건 간 인지도의 차이는 모두 유의하였다. Friedman 비모수 검정 결과 조용한 상황, $10,5,0 \mathrm{~dB}$ SNR에 서의 단어인지도는 유의하게 변화하지 않아 $(p>0.05)$ 훈련 종 료 1 개월 후, 4 개월 후까지 훈련에 의해 향상된 단어인지도가 유지되었음을 확인하였다.

문장인지도를 살펴보면 훈련 전, 훈련 후, 훈련 종료 1개월 후, 훈련 종료 4개월 후에 측정한 평균 인지도가 $68.8 \%, 84.7 \%$, 
84.1\%, 90.0\%였다(SD: 26.7, 15.3, 15.1, 10.0). $10 \mathrm{~dB}$ SNR의 소 음 상황에서 훈련 전, 훈련 후, 훈련 종료 1개월 후, 4 개월 후에 구한 평균 문장인지도는 순서대로 $50.9 \%, 80.6 \%, 80.6 \%$, 82.5\%(SD: 25.9, 12.7, 14.5, 9.0), $5 \mathrm{~dB} \mathrm{SNR}$ 에서 측정한 평균 문장인지도는 평가 시기 순서대로 $29.7 \%, 60.0 \%, 60.9 \%, 66.5 \%$ 였다(SD: 22.6, 22.0, 21.1, 14.3). 가장 어려운 듣기 조건인 $0 \mathrm{~dB}$ $\mathrm{SNR}$ 에서 측정한 평균 문장인지도는 평가 시기 순서대로 나열 하면 7.2\%, 29.3\%, 25.5\%, 21.3\%였다(SD: 10.5, 12.1, 11.8, 13.2).

분석 결과 훈련 전후 $[\mathrm{F}(1,7)=55.7, p<0.001]$ 와 듣기 조건 에 따라 $[\mathrm{F}(3,21)=97.0, p<0.001]$ 문장인지도가 유의하게 달 랐다. Bonferroni 대응별 다중비교 결과를 확인한 결과 네 가 지 듣기 조건 간 인지도의 차이는 모두 유의하였다. 조용한 상 황과 $0 \mathrm{~dB}$ SNR에서는 훈련 전에 비해 훈련 후 약 16 22\%가량 향상하였으나 $5,10 \mathrm{~dB}$ SNR 조건에서는 약 $30 \%$ 가량 향상 정
도가 더 커서 듣기 조건에 따라 훈련 전후 결과 차이가 달랐다 $[\mathrm{F}(3,21)=3.65, p<0.05]$. Friedman 비모수 검정 결과 조용한 상황, $10,5,0 \mathrm{~dB} \mathrm{SNR}$ 에서의 문장인지도는 유의하게 변화하지 않았다 $(p>0.05)$. 훈련 종료 1개월 후, 4 개월 후까지 훈련에 의 해 향상된 문장인지도가 유지되었음을 확인하였다.

\section{청능훈련에 따른 개인별 어음인지도 향상}

청능훈련 효과를 확인할 때는 훈련 후 대상자의 평균 인지도 변화뿐 아니라 대상자 개개인의 인지도 변화를 확인하는 것이 중요하다. 따라서 훈련 전과 후에 8 명 아동의 개인별 단어인지 도와 문장인지도가 얼마나 향상하였는지를 Figure 3에 제시하 였다. 인지도 향상 정도는 훈련 후 측정한 인지도에서 훈련 전 측정한 인지도를 빼 계산하였다.

Figure 3 의 상단 그림은 8명 아동 개개인의 단어인지도 향상
Figure 2. Mean word and sentence recognition scores (error bar: standard deviations) in four listening conditions obtained from the pre-training, post-training, 1-month follow-up, and 4-month follow-up tests. WRS: word recognition score, SRS: sentence recognition score, SNR: signal-to-noise ratio.
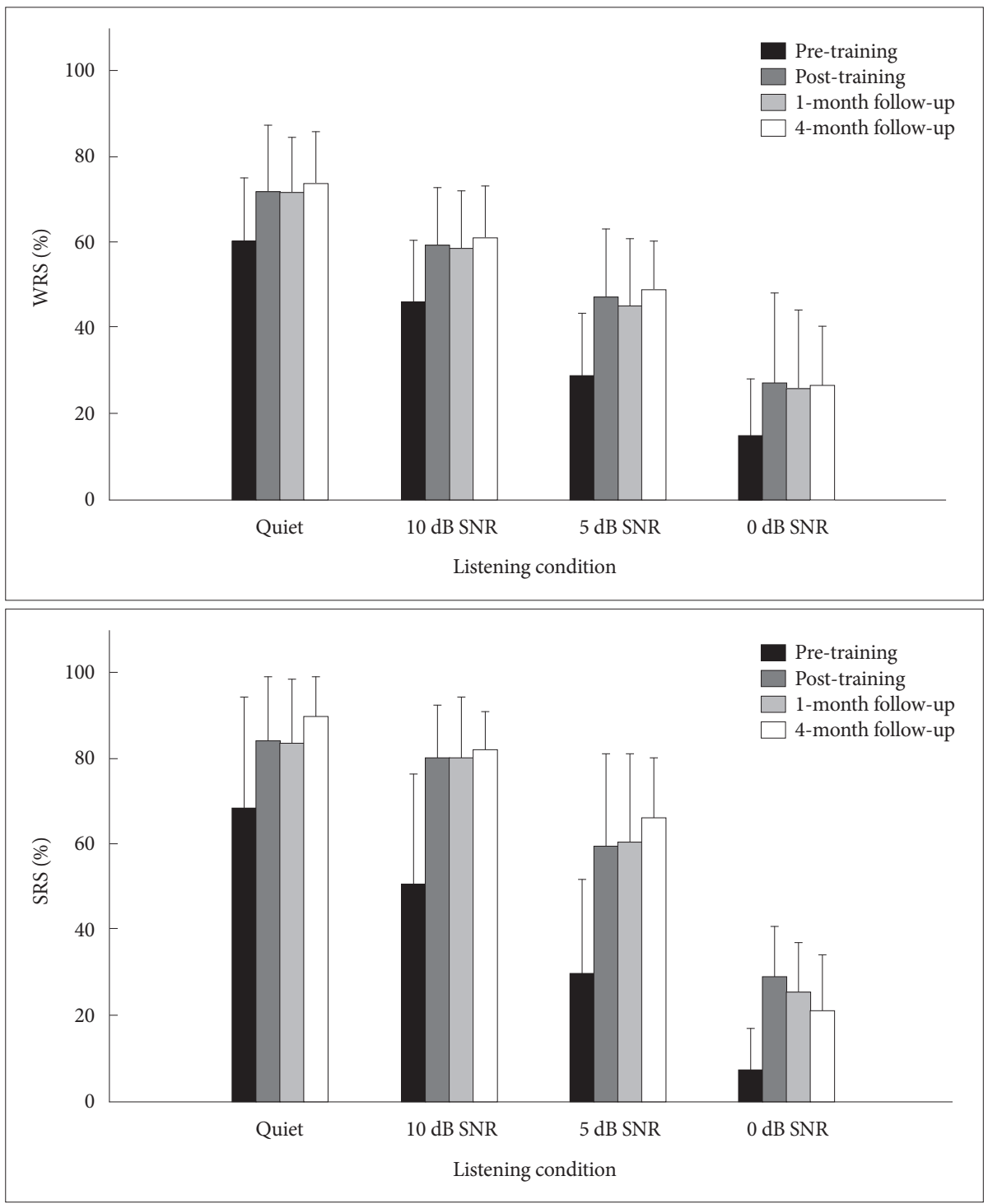
정도를, 하단 그림은 문장인지도의 향상 정도를 보여준다. 단어 인지도를 살펴보면 조용한 상황에서 평균 $11.5 \%$ 인지도가 향 상하였고, 10, 5, $0 \mathrm{~dB}$ SNR에서 약 13 18\%가량 인지도가 향 상하였다. 개인별 결과를 살펴보면 $\mathrm{S} 2, \mathrm{~S} 5, \mathrm{~S} 8$ 을 제외하고는 모 든 듣기 조건에서 단어인지도가 향상하였음을 확인할 수 있다. 특히 S6의 경우 훈련 후 조용한 상황, $10,5,0 \mathrm{~dB} \mathrm{SNR}$ 각각의 평가 조건에서 $12 \%, 20 \%, 24 \%, 36 \%$ 향상되었다. $\mathrm{S} 2$ 의 경우 5 $\mathrm{dB} \mathrm{SNR}$ 에서 훈련 후 단어인지도가 $24 \%$ 향상하였으나, 가장 어려운 평가 조건인 $0 \mathrm{~dB} \mathrm{SNR}$ 조건에서 훈련 전후 모두 $0 \%$ 의 인지도를 보여 훈련에 따른 향상이 관찰되지 않았다. S5의 경 우에도 훈련 전 $5 \mathrm{~dB}$ SNR에서는 훈련 후 $20 \%$ 증가하였으나 0 $\mathrm{dB}$ SNR 조건에서 훈련 전후 동일하게 $20 \%$ 의 인지도를 보여 훈련에 따른 향상을 확인하지 못하였다. S8의 경우 훈련 전 인 지도가 56\%였고 훈련 후 조용한 상황 속 인지도가 $52 \%$ 로 $4 \%$ 가량 감소하였다.

문장인지도를 살펴보면 조용한 상황에서 평균 $16 \%$ 가량 인
지도가 개선되었고, $10 \mathrm{~dB}$ SNR과 $5 \mathrm{~dB}$ SNR에서는 약 $30 \%$ 향상, $0 \mathrm{~dB} \mathrm{SNR}$ 에서는 약 $22 \%$ 인지도가 향상하였다. 8 명 대 상자 중 $\mathrm{S} 1, \mathrm{~S} 3$ 을 제외한 다른 대상 아동은 모든 조건에서 훈 련 후 문장인지도가 향상하였다. 특히 S4, S6, S8 아동은 10 $\mathrm{dB}$ SNR에서 40 50\%의 인지도 향상을, $\mathrm{S} 3, \mathrm{~S} 4, \mathrm{~S} 6$ 은 $5 \mathrm{~dB}$ $\mathrm{SNR}$ 에서 40 45\%의 향상을, $\mathrm{S} 3$ 과 $\mathrm{S} 6$ 아동은 $0 \mathrm{~dB}$ SNR에서 $30 ~ 35 \%$ 의 인지도 향상을 보였다. S1과 S3 역시 조용한 조건에 서 훈련 전후 문장인지도가 같아 향상이 관찰되지 않았으나 다른 평가 조건에서는 모두 인지도가 향상되었다.

\section{청능훈련에 따른 $\mathrm{ABEL}$ 설문 결과 변화와 어음인지도와의 상관 분석}

한국어 버전 일상생활 청각행동 설문지(ABEL)는 청각, 구화 및 청각적 인식 영역과 더불어 아동의 사회적 상호작용 및 대 화 기술에 대한 정보를 제공해준다. 훈련 전후 측정한 $\mathrm{ABEL}$ 평균 및 개인별 점수를 Figure 4에 제시하였다. 청능훈련 전 측
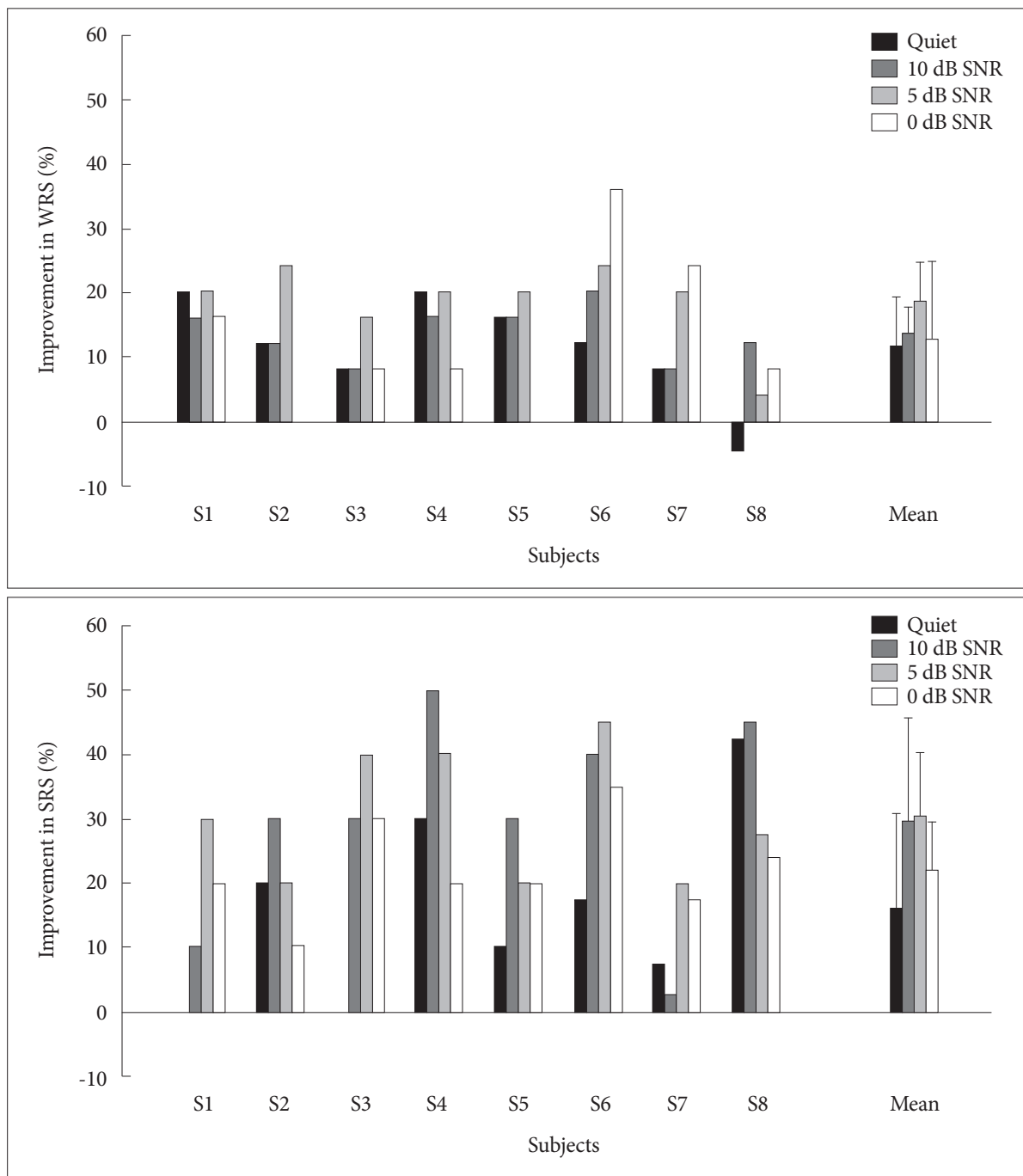

Figure 3. Individual improvements (error bar: standard deviations) in word and sentence recognition scores. S: subject, WRS: word recognition score, SRS: sentence recognition score, SNR: signal-tonoise ratio. 
정한 $\mathrm{ABEL}$ 점수는 평균 94.6점(SD: 14.1)이었고 8주의 훈련 후 같은 설문을 시행한 결과 평균 110.3점(SD: 11.5)으로 훈련 후 약 15.6점가량 상승하였다. 비모수 분석 결과 훈련 전보다 훈련 후 $\mathrm{ABEL}$ 점수가 유의미하게 향상하였다 $(p<0.05)$. 훈련 전과 훈련 후 개개인별 점수를 비교해 보면 대상 아동 8 명 중 $\mathrm{S} 4$ 는 최소 1점, $\mathrm{S} 2$ 는 최대 55점 향상하였다.

위에 열거하였듯이 대부분의 대상 아동은 청능훈련 후 객관 적 단어인지도, 문장인지도뿐 아니라 설문 평가 결과가 향상하 였다. 객관적 어음인지도의 향상 정도와 주관적 설문 결과의 변화 간 상관성을 분석한 결과, 유의한 상관성이 없었다 $(p>$ 0.05). 즉, 객관적 인지도 결과에서 아동의 단어인지도 혹은 문 장인지도가 향상하였을수록 부모가 답한 $\mathrm{ABEL}$ 설문 결과가 상관성 있게 향상하지 않았음을 의미한다. 훈련 후 조용한 상황 과 $10,5,0 \mathrm{~dB} \mathrm{SNR}$ 소음 상황에서 측정한 단어인지도 간 변화 에도 서로 상관성이 없었다. 그러나 훈련 후 조용한 상황에서 문장인지도가 많이 향상하였을수록 $10 \mathrm{~dB} \mathrm{SNR}$ 의 소음하 문 장인지도가 유의하게 향상하였고 $(\mathrm{r}=0.79, p<0.05)$, 훈련 후 $5 \mathrm{~dB} \mathrm{SNR}$ 에서 소음하 문장인지도가 많이 향상한 아동일수록 $0 \mathrm{~dB} \mathrm{SNR}$ 의 소음하 문장인지도가 유의하게 향상하였다 $(\mathrm{r}=$ $0.79, p<0.05)$.

\section{DISCUSSIONS}

청각 보조기기에 다양한 음향학적 기술 발전이 이루어졌으 나 여전히 보청기 착용만으로 다양한 소음 속에서 난청인의 의 사소통의 불편함을 해소하기에 한계가 있다. 이러한 한계를 극
복하기 위해 다양한 소음하 청능훈련 연구가 진행되었고 긍정 적인 훈련 효과가 다수 보고되었으며(Burk \& Humes, 2008; Ferguson \& Henshaw, 2015; Ferguson et al., 2014; Jo et al., 2013; Lee et al., 2016a; Yeo et al., 2014), 청능훈련 및 재활의 중요성이 강조되었다. 청각장애를 가진 아동의 경우 건청 아동 에 비해 상대적으로 듣기 및 언어 발달이 지연되어 있으므로 난 청 아동에게 조기에 청능훈련을 시작하는 것은 매우 중요하다 (Stelmachowicz et al., 2004). 이러한 사실이 알려져 있음에도 불구하고 아동에게 적용 가능한 청능훈련 도구의 부족, 훈련에 참여 가능한 아동 모집의 어려움, 기타 행정적, 경제적 지원 등 의 부족으로 인하여 난청 아동을 대상으로 청능훈련의 효과를 밝힌 연구가 비교적 부족한 편이다.

본 연구에서는 보청기 착용 난청 아동 8 명을 대상으로 8 주 간 소음하 문장인지 청능훈련을 시행하고 훈련의 효과가 어떠 한지, 훈련의 효과가 훈련 종료 4개월 후까지 유지되는지 평가 하였다. 분석 결과 훈련 전보다 훈련 후 조용한 상황뿐 아니라 $10,5,0 \mathrm{~dB}$ SNR 소음환경에서 단어인지도와 문장인지도가 향 상되는 긍정적인 훈련 효과를 확인하였다. 훈련 종료 1개월 후, 4개월 후까지도 인지도가 유의하게 감소하지 않아 훈련의 효과 가 유지되었음을 확인하였다. 본 연구에 참여한 대상 아동의 경우 조용한 상황에서 측정한 단어인지도와 문장인지도가 평 균 $60 \%$ 로 조용한 상황에서 의사소통하는 데는 매우 큰 어려 움은 없으나 $5 \mathrm{~dB}$ SNR에서는 평균 $30 \%$ 미만의 인지도를, 0 $\mathrm{dB}$ SNR에서는 평균 $15 \%$ 미만의 인지도를 보여 일상적인 교실 소음 상황인 0 5 dB SNR (Crandell \& Smaldino, 2000)에서 의사소통에 어려움을 보이는 아동들이었다. 훈련 후 개선된 정
Figure 4. Individual and mean ABEL scores (error bar: standard deviations) obtained from pre-training and post-training tests. ABEL: auditory behavior in everyday life questionnaire, $\mathrm{S}$ : subject.

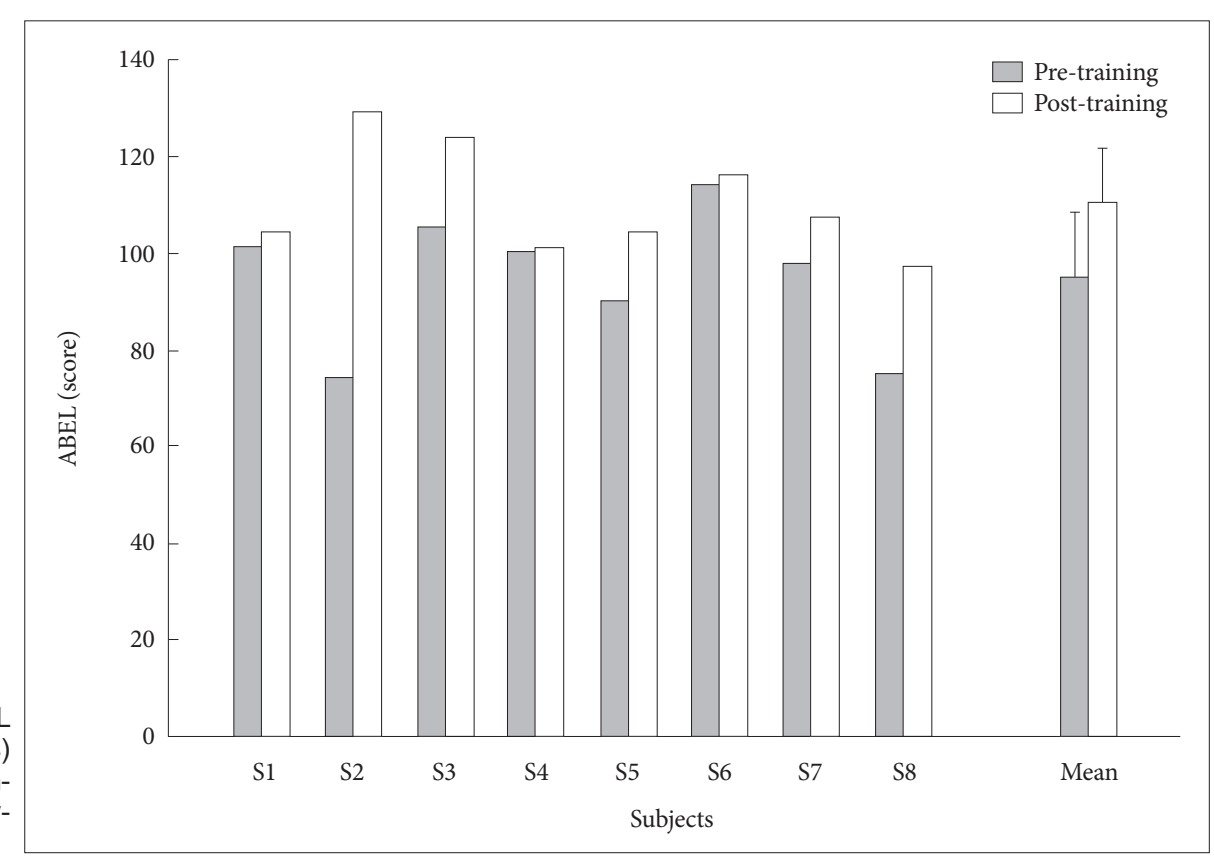


도에는 개인 간 차이가 있었으나, 조용한 상황뿐 아니라 10,5 , $0 \mathrm{~dB} \mathrm{SNR}$ 소음 조건 모두에서 훈련 후 인지도가 유의미하게 개선되었다. 난청 아동을 대상으로 친숙한 단어와 주제를 가진 문장을 이용하여 소음하 청능훈련을 실시한 Sullivan et al. (2013)은 청능훈련 후 소음하 어음인지도가 향상하였음을 보 고하였다. 어음이 아닌 다른 자극음을 이용한 국내외 아동 청 능훈련 연구에서도 아동에게 훈련의 효과가 긍정적이었다고 보고하였다. 예를 들면 Choi et al.(2017b), Fu et al.(2015), Rochette et al.(2014)은 음악을 이용한 청능훈련을 시행한 이후 아동의 어음인지 능력이 개선되었다고 하였고, Oba et al.(2011) 은 소음하에서 숫자를 이용하여 청능훈련을 시행한 결과 인공 와우 착용 아동의 어음인지도가 향상하였다고 하였다. Lotfi et al.(2016)은 훈련 후 난청 아동의 청각 측분별 능력의 향상을 밝 혔고, Alonso \& Schochat(2009)은 중추청각처리장애 아동을 대상으로 8주간 청능훈련을 실시 후 아동들의 청각기억 능력 이 향상되었다고 하였다. 따라서 아동의 경우 아동이 선호하는 자극음을 다양하게 사용하여 청능훈련을 시행하면 자극음의 종류에 상관없이 어음인지도 개선을 기대해 볼 수 있겠다.

본 연구에서는 훈련 후 객관적 인지도뿐 아니라 한국어 버전 일상생활 청각행동 설문지(ABEL) 점수가 유의하게 개선됨을 확인하였다. 개인별 $\mathrm{ABEL}$ 점수를 확인하였을 때, $\mathrm{ABEL}$ 결과가 훈련 후 최소로 상승(1점 상승)한 아동(S4)은 실제로 객관적 어 음인지 결과에서는 $10 \mathrm{~dB} \mathrm{SNR}$ 에서의 문장인지도가 $50 \%, 5 \mathrm{~dB}$ $\mathrm{SNR}$ 에서의 문장인지도는 $40 \%$ 가량 상승한 아동이었다. 반대로 $\mathrm{S} 2$ 아동의 경우 훈련 후 $\mathrm{ABEL}$ 점수가 최대로 향상한 경우였으 나(55점 향상), $5 \mathrm{~dB} \mathrm{SNR,} 0 \mathrm{~dB} \mathrm{SNR}$ 조건에서의 문장인지도 개 선 정도가 다른 아동에 비하면 더 적은 편이었다. 통계 분석 결 과에서도 객관적 인지도의 향상과 주관적 설문 결과의 향상 정 도 간 유의미한 상관성이 없었다. 따라서 훈련에 따른 아동의 의사소통 능력의 향상과 부모가 주관적으로 느끼는 아동의 청 각 행동의 변화 정도가 관련성을 가지지 않음을 알 수 있었다.

본 연구의 제한점은 표본 수가 작다는 점이다. 본 연구에서는 8 주간 매주 청능훈련에 참여가 가능하고 훈련 종료 1 개월 후, 4 개월 후에도 재평가를 위해 아동과 보호자가 방문이 가능하여 야 하였으므로 훈련 효과를 일반화할 수 있도록 30명 이상의 대 상 아동을 모집하지는 못하였다. 본 연구에서는 최대한 비슷한 연령대와 비슷한 평균 순음 청력역치를 보이는 난청 아동이 대상 자로 참여하였으나 난청 시작 시기, 보청기 착용 기간, 주파수별 청력, 아동의 전반적인 인지적 능력, 착용 중인 보장구 종류 등의 다양한 요인이 아동의 인지도에 영향을 줄 수 있다. 본 연구 대상 아동 8 명 중 7명은 양이에 보청기를 사용하고 있었고 나머지 1명 (S5)만 좌측 귀에 보청기를 우측 귀에는 인공와우를 착용하고 있 었다. S5 대상 아동은 $0 \mathrm{~dB}$ SNR 조건에서 훈련 전후 인지도가

동일하여(20\%) 훈련 효과가 관찰되지 않았으나, 나머지 평가 조 건에서 어음인지도가 10 30\%가량 향상되었다. 위에서 언급한 다양한 요인을 통제하기에는 8명의 대상자 수가 부족하므로 향 후 연구에서는 보다 많은 아동을 대상으로 하는 연구가 필요하 겠다. 마지막으로, 본 연구에서는 소음하 문장인지하기를 주 훈 련 내용으로 시행하였으나 향후 아동을 대상으로 하는 청능훈 련 연구에서는 어음뿐 아니라 보다 다양한 자극음을 아동이 쉽게 접하는 배경소음 속에서 제시하는 등 아동의 실제 일상생 활과 유사한 평가 조건에서 훈련을 시행하는 것이 필요하다.

요약하면 본 연구에서는 보청기 착용 난청 아동 8 명을 대상 으로 8주간 청능훈련을 시행하였다. 훈련 후 조용한 상황뿐 아 니라 다양한 소음 상황에서 아동의 단어인지도와 문장인지도 가 향상하였다. 훈련 종료 1 개월 후와 4개월 후에 실시한 재평 가 결과 훈련의 효과가 유지되고 있음을 확인하였다. 객관적 어 음인지도와 더불어 부모의 주관적 설문 결과에서도 훈련 전보 다 훈련 후 아동의 청각적 행동 등이 개선되었다고 보고되었다. 따라서 소음하 의사소통에 어려움을 겪는 보청기 착용 아동에 게 소음하 문장인지 청능훈련을 실시하여 긍정적인 효과를 기 대할 수 있겠다.

중심 단어 : 아동 청능훈련·청각 재활·난청·소음하 어음인지.

\section{Ethical Statement}

The study was approved by Institutional Review Board of Hallym University of Graduate Studies (IRB: HUGSAUD689521).

\section{Acknowledgments \\ N/A}

\section{Declaration of Conflicting Interests \\ There are no conflict of interests.}

\section{Funding}

N/A

\section{Author Contributions}

Y.L. performed experiments, analyzed data and wrote a draft of the manuscript; H.H. designed and performed experiments; J.L. reviewed the final version of this manuscript as the corresponding author.

\section{ORCID iDs}

Yewon Lee

Jae Hee Lee

\author{
https://orcid.org/0000-0002-7565-7731 \\ https://orcid.org/0000-0002-4152-6434
}

\section{REFERENCES}

Ahn, P. \& Lee, K. (2016). Development of environmental sounds for auditory training. Audiology and Speech Research, 12(2), 82-88.

Alonso, R. \& Schochat, E. (2009). The efficacy of formal auditory training in children with (central) auditory processing disorder: Behavioral and electrophysiological evaluation. Brazilian Journal of Otorhinolaryngology, 75(5), 726-732.

Baek, S. S. \& Lee, J. H. (2016). Development of crossword puzzles for auditory training. Audiology and Speech Research, 12(2), 103-108. 
Burk, M. H. \& Humes, L. E. (2008). Effects of long-term training on aided speech-recognition performance in noise in older adults. Journal of Speech, Language, and Hearing Research, 51(3), 759-771.

Choi, J., Yoon, K., \& Jang, H. (2017a). Validity and reliability of Korean version of the auditory behavior in everyday life questionnaire. Audiology and Speech Research, 13(1), 19-27.

Choi, W. J., Oh, S. H., \& Bahng, J. (2017b). Efficacy of music training on speech recognition and working memory in children wearing cochlear implants. Audiology and Speech Research, 13(1), 70-77.

Crandell, C. C. \& Smaldino, J. J. (2000). Classroom acoustics for children with normal hearing and with hearing impairment. Language, Speech, and Hearing Services in Schools, 31(4), 362-370.

Ferguson, M. A., Henshaw, H., Clark, D. P., \& Moore, D. R. (2014). Benefits of phoneme discrimination training in a randomized controlled trial of 50- to 74-year-olds with mild hearing loss. Ear and Hearing, 35(4), e110-e121.

Ferguson, M. A. \& Henshaw, H. (2015). Auditory training can improve working memory, attention, and communication in adverse conditions for adults with hearing loss. Frontiers in Psychology, 6, 556.

$\mathrm{Fu}$, Q. J., Galvin, J. J. 3rd., Wang, X., \& Wu, J. L. (2015). Benefits of music training in Mandarin-speaking pediatric cochlear implant users. Journal of Speech, Language, and Hearing Research, 58(1), 163-169.

Green, T., Faulkner, A., \& Rosen, S. (2019). Computer-based connectedtext training of speech-in-noise perception for cochlear implant users. Trends in Hearing, 23, 2331216519843878.

Henshaw, H. \& Ferguson, M. A. (2013). Efficacy of individual computerbased auditory training for people with hearing loss: A systematic review of the evidence. PLoS One, 8(5), e62836.

Jamieson, D. G., Kranjc, G., Yu, K., \& Hodgetts, W. E. (2004). Speech intelligibility of young school-aged children in the presence of real-life classroom noise. Journal of the American Academy of Audiology, 15(7), 508-517.

Jo, Y. Y., Bahng, J., \& Lee, J. H. (2013). Case study of auditory training for an elderly hearing aid user. Audiology and Speech Research, 9(2), 190194.

Kim, Y. T. (2000). Content and reliability analyses of the preschool receptive-expressive language scale (PRES). Communication Sciences and Disorders, 5(1), 1-25.

Klatte, M., Bergström, K., \& Lachmann, T. (2013). Does noise affect learning? A short review on noise effects on cognitive performance in children. Frontiers in Psychology, 4, 578.

Klatte, M., Lachmann, T., \& Meis, M. (2010). Effects of noise and reverberation on speech perception and listening comprehension of children and adults in a classroom-like setting. Noise and Health, 12(49), 270282.

Lee, J. I., Bang, J., \& Lee, J. H. (2017). Development and verification of auditory training tool for children. Audiology and Speech Research, 13(2), 123-132.

Lee, J. H., Cho, S. J., Kim, J. S., Jang, H. S., Lim, D. H., Lee, K. W., et al. (2010). Korean Speech Audiometry (KSA). Seoul: Hakjisa.

Lee, J. H., Lee, S. G., \& Bahng, J. (2016a). Case study of auditory training for long-term users of hearing aids with poor word recognition. Audiology and Speech Research, 12(3), 190-194.

Lee, J. W., Yi, D. W., Lee, J., \& Lee, J. H. (2016b). A preliminary evaluation of multiple-choice sentences developed for auditory training. Audiology and Speech Research, 12(2), 97-102.

Lim, E. H. \& Bahng, J. (2016). Preliminary study for development of audi- tory training tool using story and question. Audiology and Speech Research, 12(2), 109-114.

Lotfi, Y., Moosavi, A., Abdollahi, F. Z., Bakhshi, E., \& Sadjedi, H. (2016). Effects of an auditory lateralization training in children suspected to central auditory processing disorder. Journal of Audiology and Otology, 20(2), 102-108.

Mishra, S. K. \& Boddupally, S. P. (2018). Auditory cognitive training for pediatric cochlear implant recipients. Ear and Hearing, 39(1), 48-59.

Mishra, S. K., Boddupally, S. P., \& Rayapati, D. (2015). Auditory learning in children with cochlear implants. Journal of Speech Language and Hearing Research, 58(3), 1052-1060.

Nanjundaswamy, M., Prabhu, P., Rajanna, R. K., Ningegowda, R. G., \& Sharma, M. (2018). Computer-based auditory training programs for children with hearing impairment-A scoping review. International Archives of Otorhinolaryngology, 22(1), 88-93.

Oba, S. I., Fu, Q. J., \& Galvin, J. J. 3rd. (2011). Digit training in noise can improve cochlear implant users' speech understanding in noise. Ear and Hearing, 32(5), 573-581.

Park, S. \& Han, W. (2019). A systematic review for auditory training effect based on Korean database. Audiology and Speech Research, 15(3), 145159.

Park, Y., Cheong, J., \& Jang, Y. (2001). Noise condition and characteristics for an elementary school in urban area. Journal of Environmental Science and Technology Research Center, 11(1), 23-30.

Rayes, H., Al-Malky, G., \& Vickers, D. (2019). Systematic review of auditory training in pediatric cochlear implant recipients. Journal of Speech, Language, and Hearing Research, 62(5), 1574-1593.

Rochette, F. \& Bigand, E. (2009). Long-term effects of auditory training in severely or profoundly deaf children. Annals of the New York Academy of Sciences, 1169, 195-198.

Rochette, F., Moussard, A., \& Bigand, E. (2014). Music lessons improve auditory perceptual and cognitive performance in deaf children. Frontiers in Human Neuroscience, 8, 488.

Roman, S., Rochette, F., Triglia, J. M., Schön, D., \& Bigand, E. (2016). Auditory training improves auditory performance in cochlear implanted children. Hearing Research, 337, 89-95.

Shin, J. B. \& Lee, J. H. (2010). Effects of the target talker gender and the number of competing talkers on acceptable noise level (ANL) of Korean normal-hearing adults. Audiology, 6(2), 146-152.

Stelmachowicz, P. G., Pittman, A. L., Hoover, B. M., Lewis, D. E., \& Moeller, M. P. (2004). The importance of high-frequency audibility in the speech and language development of children with hearing loss. Archives of Otorhinolaryngology-Head and Neck Surgery, 130(5), 556-562.

Sullivan, J. R., Thibodeau, L. M., \& Assmann, P. F. (2013). Auditory training of speech recognition with interrupted and continuous noise maskers by children with hearing impairment. The Journal of the Acoustical Society of America, 133(1), 495-501.

Valente, D. L., Plevinsky, H. M., Franco, J. M., Heinrichs-Graham, E. C., \& Lewis, D. E. (2012). Experimental investigation of the effects of the acoustical conditions in a simulated classroom on speech recognition and learning in children. The Journal of the Acoustical Society of America, 131(1), 232-246.

Wu, J. L., Yang, H. M., Lin, Y. H., \& Fu, Q. J. (2007). Effects of computer-assisted speech training on Mandarin-speaking hearing-impaired children. Audiology and Neurotology, 12(5), 307-312.

Yeo, S., Bahng, J., \& Lee, J. H. (2014). Efficacy of auditory training using sentences in noise for hearing aid users. Audiology, 10(1), 65-75. 